\title{
THE RADIATION INTEGRATOR IN VACUO, AN INSTRUMENT FOR THE STUDY OF RADIANT HEAT RECEIVED FROM THE SUN.
}

\author{
BY P. A. BUXTON. \\ Formerly Fellow of Trinity College, Cambridge; London School of Hygiene \\ and Tropical Medicine.
}

(With 2 Text-figures.)

THE radiant heat of the sun is of obvious importance to hygiene, not only because it is the basis of all life, but also because of its immediate bearing on sunstroke, heliotherapy, seasons and climates. It is necessary for us to study solar radiation as it actually strikes plant and animal and the surface of the earth, and to do this at all seasons and at many points on the surface of the globe. We are most of us apt to think of climate in terms of common meteorological elements, such as temperature, humidity and rainfall; we forget that there is a "solar climate," and that an object exposed to the sun may receive very different amounts of radiant heat at different seasons, though the effect of these seasonal changes may not show itself in the shade temperature. An excellent example is the climate of the Samoan Islands, which is discussed below.

Though radiant heat coming from the sun is so important, it receives little attention from hygienists, and indeed from biologists generally, partly because it is difficult to study. Physicists have devised a number of "pyrheliometers," which are expensive, complex instruments, suited only to large observatories, where a staff is maintained skilled in their use, and in the interpretation of the results which they give. We biologists on the other hand have used black bulb thermometers in vacuo, and other instruments, which are unsatisfactory because the results they give are empirical, and cannot be reduced to physical units. We now want if possible to devise instruments, which will be fairly cheap to make and standardize, and easy to read and instal; they should be able to stand out in any weather, which the pyrheliometers cannot do; it is also very much to be desired that their readings should be reducible to strict physical units.

It appears that the instrument here described fulfils most of these conditions and is capable of improvement. It has the additional advantage that it integrates its results. It has been rather severely criticized by one or two physicists, on the ground that, though it was successfully standardized under conditions prevalent in Samoa (page 291), we have no reason to suppose that its thermal efficiency would be the same under other climatic conditions. 
That is probably true enough, but if the biologists are to wait till physics produces a perfect instrument, they may wait a long time, and in the meanwhile are neglecting the study of an important element in climate.

The work which is discussed in the present paper was done at the Hospital, Apia, Samoa, where I was working for the London School of Hygiene and Tropical Medicine. The climate of Apia has already been observed for many years, so that reliable means for temperature, etc., are available. Moreover, the temperature is remarkably constant throughout the year, and this was essential to the experiments here described. Table I shows the unvarying character of the temperature. The "mean temperatures" are based on 24 hourly means for the period 1890-1919. The other records are for the period 1922-1925 only. These data are derived from the records of the Observatory, at sea level, and about two miles from the Hospital (altitude 145 feet), at which most of my work was done. We know that there are no significant differences of temperature between Observatory and Hospital. Mean shade temperatures for twelve consecutive months are also given in Table III.

Table I. Temperatures of months with highest and lowest mean temperatures and of year, Apia Observatory.

\begin{tabular}{|c|c|c|c|c|c|}
\hline Month & $\begin{array}{l}\text { Mean temp. } \\
{ }^{\circ} \mathrm{C} \text {. }\end{array}$ & $\begin{array}{c}\text { Mean max. } \\
{ }^{\circ} \mathrm{C} .\end{array}$ & $\begin{array}{l}\text { Mean min. } \\
{ }^{\circ} \mathrm{C} \text {. }\end{array}$ & $\begin{array}{l}\text { Abs. max. } \\
{ }^{\circ} \mathrm{C} .\end{array}$ & $\begin{array}{l}\text { Abs. min. } \\
{ }^{\circ} \mathrm{C} .\end{array}$ \\
\hline July $\ldots$ & $25 \cdot 01$ & $28 \cdot 82$ & $23 \cdot 10$ & $30 \cdot 6$ & $20 \cdot 2$ \\
\hline & $26 \cdot 28$ & $28 \cdot 87$ & $23 \cdot 14$ & & 20.2 \\
\hline & 25.78 & $29 \cdot 20$ & $23 \cdot 15$ & $32 \cdot 4$ & $19 \cdot 8$ \\
\hline
\end{tabular}

Though the temperature is nearly constant, one knows that the amount of radiant heat received in Apia varies from month to month. Apia lies $13^{\circ} 49^{\prime}$ South; therefore the longest day (21st December) is $12 \mathrm{hrs.} .57$ mins., the shortest (20th June) 11 hrs. 19 mins. The sun is vertically overhead at noon on 12th February. After that it continues going north until 21st June, when it has a maximum zenith angle of $37^{\circ} 12^{\prime}$. On 29th October, it is again overhead, and on 21st December, it has its maximum southerly declination when the zenith angle is $9^{\circ} 40^{\prime}$ South. One would therefore expect solar radiant heat to be most intense in February and October, and in general more intense in the summer (October to March) than in the winter (April to September). But the case is complicated by the fact that summer is the cloudy season. Angenheister gives monthly means of duration of sunshine for a period of six years; August has the highest value, 200 hours; February the lowest, 133 hours (monthly values adjusted to equal months of 30 days). We have reason, therefore, to expect a seasonal change in the solar climate of Apia, though the differences in radiant heat received hardly affect the shade temperature; this is because of the thermostatic effect of the Pacific Ocean. In other words any object exposed to the sun, for instance a plant, or insect, or the island itself, is receiving different amounts of radiant heat at different seasons though the shade temperature is nearly constant.

The instrument which I wish to describe is based upon W. E. Wilson's 
"Radio Integrator," and the principle upon which they both work is that a bulb containing a volatile liquid is exposed to the sun and becomes heated, causing some fluid to be vaporized, to diffuse down the stem, and recondense at the bottom, which is kept in a ventilated shelter at shade temperature. The amount of distillate is measured in the graduated stem. But in the Wilson instrument, the bulb is naked and therefore cooled by wind and by convection currents, whereas the bulb of the new instrument is enclosed in a spherical vessel exhausted to a high vacuum. The bulb of my instrument is blackened with carbon; in Wilson's instrument the alcohol is rendered opaque with a dark dye. I find that an instrument similar to mine has been suggested (Glazebrook's Dictionary of Applied Physics) but so far as I know it has not been made and used.

The physical principles involved appear to be as follows: the black bulb is at the temperature of a black bulb thermometer in vacuo, exposed under similar conditions to the sun; the graduated stem is at shade temperature. In saying this, I neglect the cooling. effect of the evaporation of alcohol in the bulb and the heating effect of its condensation in the stem, because the total amount of alcohol distilled is only 2 or 3 c.c. per day, and all through that period the bulb is receiving radiant heat, and the stem is surrounded by an immeasurable quantity of air at shade temperature.

Neglecting for the moment the shape and dimensions of the apparatus, the amount of distillate depends on the difference between the vapour pressures of alcohol in bulb and stem, and those vapour pressures depend on the temperatures of the bulb and stem. Taking the vapour pressures of alcohol given in Landolt and Börnstein's tables, if the bulb is at $60^{\circ} \mathrm{C}$. and the stem at $25^{\circ} \mathrm{C}$. the difference in vapour pressures is $291 \mathrm{~mm}$. of mercury, but if the bulb is at $60^{\circ} \mathrm{C}$. and the stem at $30^{\circ} \mathrm{C}$. the difference in vapour pressures is $272 \mathrm{~mm}$. of mercury. So that alterations in the volume of distillate, due to differences between the temperatures in bulb and stem, are decidedly less than if the volume of distillate were directly proportional to the difference in temperature. The volume of distillate is also determined by the coefficient of diffusion of alcohol vapour, which varies with temperature; it also depends upon the shape and dimensions of the apparatus, being proportional to the cross-section of the tube, which leads from bulb to stem, and inversely proportional to its length. It is, therefore, necessary that the dimensions of the apparatus should be standardized.

The new instrument is considerably smaller than Wilson's, so that it is ,more portable and less likely to be broken; also, as the bulb is smaller and contains less alcohol, the time lag while it heats or cools, as the rate of radiation changes, is reduced. The new instrument is easily set at the end of an observation by turning it upside down till the alcohol has filled the bulb. It costs about fifteen shillings in London if small numbers are made.

The first instruments of the new type which were made had unblackened bulbs, and differed in other points of detail from that shown in Text-fig. 1 . 
Into one of these I introduced 10 c.c. of absolute ethyl alcohol, that is to say, enough to fill the bulb; I found that the amount distilled never reached 1 c.c. per day in Apia, even in cloudless weather (February and March). Clearly a liquid which evaporates more readily than absolute ethyl alcohol (B.P. $78^{\circ}$ C.) was required, and anaesthetic ether (B.P. $35^{\circ}$ C.) was chosen, from among the very few pure liquids available in Samoa. It is important to adjust matters so as to get a measurable distillate even in dull weather, but so as not to allow the bulb to become more than half empty in bright weather. Using ether, with the unblackened bulb, these conditions are satisfied with an exposure from 9 a.m. to noon, but not with a longer exposure.

Table II shows the results obtained, using one individual instrument from June 1924 to November 1925.

Table II. Results of the ether integrator, 9 a.m. to 12 noon

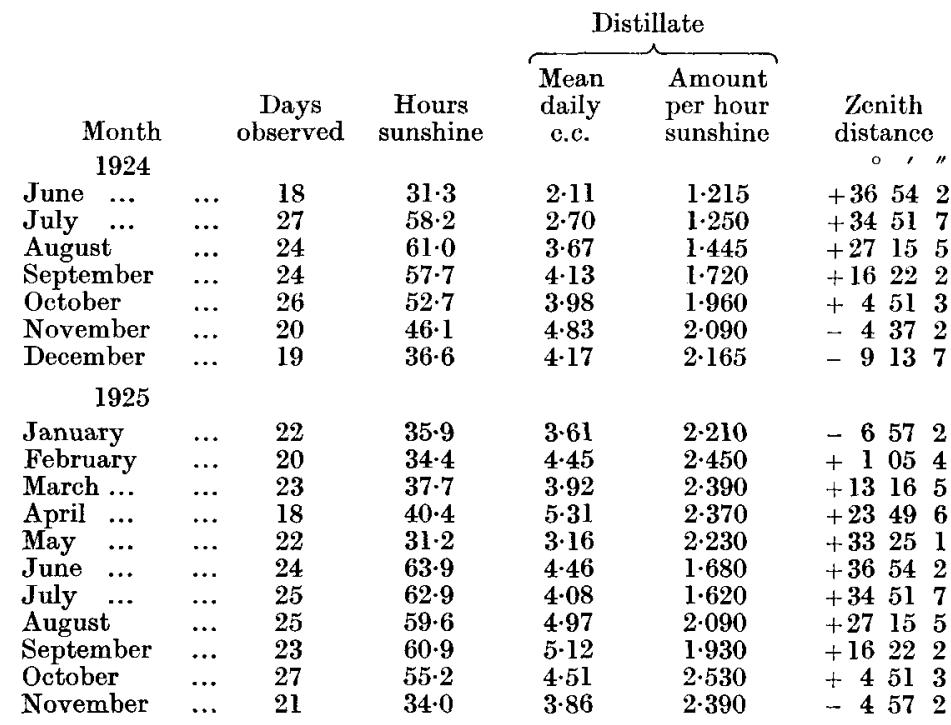

"Hours of sunshine" are from a Campbell Stokes instrument at the Observatory: only the readings from 9 a.m. to noon, on the actual days on which the ether instrument was read, are included. Very close correspondence between "hours of sunshine" and "amount of distillate per hour of sunshine" cannot be expected, because the Campbell Stokes instrument makes a record even when the sun is shining through haze, and we know that under these circumstances the amount of radiant heat reaching the earth is greatly reduced. Moreover, the Observatory is more than two miles from the Hospital where the ether bulb is installed and we have no reason to presume that the hours of sunshine observable at the two stations are closely similar. "Zenith distance" is the monthly mean angular distance of the sun at noon from the zenith, calculated by Mr A. Thomson, Director of Apia Observatory.

The results obtained with the instrument filled with ether are empirical. 
As the bulb is not blackened, an unknown amount of heat passes through the instrument; this prevents one from trying to reduce the results to strict physical units. But as they stand they are interesting: they show that the amount of heat received from $9 \mathrm{a} . \mathrm{m}$. to noon shows distinct seasonal incidence, and that the maxima occur in February and October, corresponding to the time when the sun is vertically overhead at noon. This variation is apparent if we disregard the difference between clear and cloudy weather, and study the daily mean volumes of distillate, month by month. It is also apparent in the amounts of distillate collected per hour of sunshine.

I felt that these early results were encouraging and Mr Thomson, who was on leave in Canada, kindly undertook to have more instruments made, in

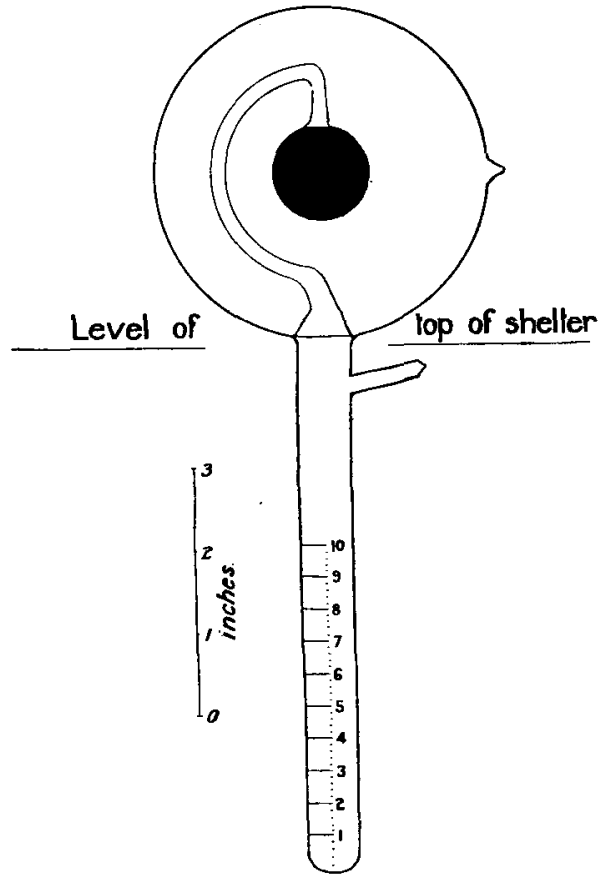

Text-fig. 1. Radiation integrator in vacuo, as described in text.

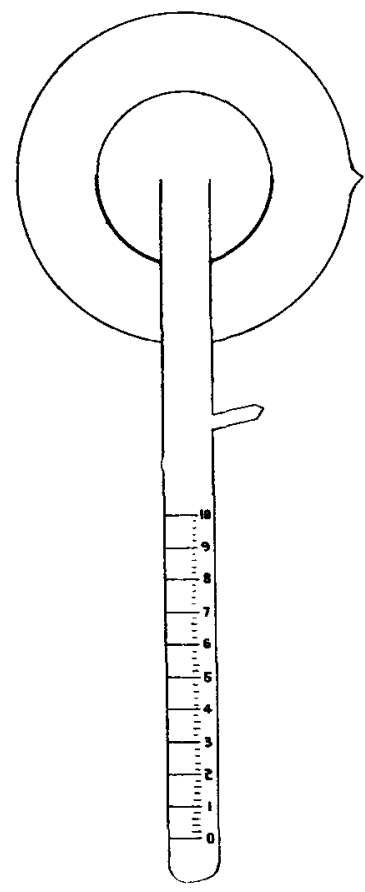

Text-fig. 2. Suggested design for improved pattern, in section.

which small improvements were embodied. We are most grateful to the Physics Department of Toronto University for placing their skill and knowledge at his disposal and for making the instruments.

The inner bulb of the new instrument (Text-fig. 1) was blackened with carbon. In order to avoid absorbed gases being subsequently given off, the bulbs were heated two or three times, until a pressure gange showed no indication of gases being given off in the course of days. Great care was taken to exhaust the outer bulb to the highest vacuum possible. The glass blower was instructed to make six instruments, as similar to one another as possible, but the dimensions were not carefully standardized. 
The bulbs were filled with absolute ethyl alcohol, at atmospheric pressure; they were not exhausted of air. The shape and size of these instruments is shown exactly in Text-fig. 1. It was found that with these black-bulbed instruments, filled with alcohol, a measurable distillate $(0.1$ to 0.2 c.c.) was obtained on days of continuous light rain, and that on a continuously bright day not more than 3.5 c.c. was ever distilled between sunrise and sunset. The bulbs (which hold 10 c.c.) were therefore not greatly depleted if the instrument was exposed all day. It was also found that there was no back distillation at night into the bulb from the stem; we therefore read and set the instruments at 9 a.m. every day, an hour which we found more convenient than dawn. It does not, of course, follow that there would be no back distillation in a country with freer radiation at night, and a greater difference between day temperature and night temperature.

It was hoped that the six instruments would give identical, or nearly identical readings, if exposed side by side; but it was found that they gave readings, which were not merely different, but erratically so. The probable reason was that the exhaustion of the outer bulbs was not equally complete, so that some instruments were sensitive to wind, others not.

After the instruments had been run side by side for some months, it was found that the readings of two bore a nearly constant relationship to one another, but that the readings of the other four did not do so. The readings obtained with these two are as follows: the amount of alcohol distilled by $B$ has been reduced to 100 , to allow of easy comparison.

\begin{tabular}{|c|c|c|c|}
\hline \multirow[b]{2}{*}{ Period } & \multirow{2}{*}{$\begin{array}{l}\text { No. } \\
\text { of days }\end{array}$} & \multicolumn{2}{|c|}{ Instruments } \\
\hline & & A. & $B$. \\
\hline Dec., Jan. ... & 59 & 122 & 100 \\
\hline Feb., Mar., April & $\ldots$ & 127 & 100 \\
\hline Five months & 145 & 125 & 100 \\
\hline
\end{tabular}

Instrument $B$ has been exposed for 12 months, at Apia, under absolutely uniform conditions, and the results are shown in Table III. It must be remembered that the instrument was exposed for the whole day (and not for the period from 9 a.m. to noon, as in the case of the earlier instruments filled with ether, see Table II).

In Table III "hours of sunshine" are those recorded by the Campbell Stokes instrument installed at the Observatory, on the actual days on which instrument $B$ was exposed. In discussing the original ether-filled instruments I pointed out (p. 288) that no very close correspondence could be expected between the amount of distillate and the hours of sunshine. In the case of instrument $B$, which was exposed all day (and not merely from 9 a.m. to noon), there is an additional source of discrepancy, because the hours of sunshine may have occurred at noon, or early or late in the day. They are all recorded by the Campbell Stokes instrument, but the effect of the sun at different times of day upon the black-bulbed instruments will be by no means equal. In the columns which give the distillate as "daily mean" and "per- 
Table III. Results obtained with instrument $B$ exposed all day, flled with alcohol.

\begin{tabular}{|c|c|c|c|c|c|c|c|c|}
\hline & & & & Distilla & & & Blacl & hollb \\
\hline & & & & & Amount & Mean & Dialc & Dino \\
\hline Month & $\begin{array}{c}\text { Days } \\
\text { observed }\end{array}$ & $\begin{array}{l}\text { Hours } \\
\text { sunshine }\end{array}$ & $\begin{array}{l}\text { Daily } \\
\text { mean } \\
\text { c.c. }\end{array}$ & $\begin{array}{c}\% \text { of } \\
\text { annual } \\
\text { total }\end{array}$ & $\begin{array}{c}\text { per hour } \\
\text { sunshine } \\
\text { c.c. }\end{array}$ & $\begin{array}{l}\text { shade } \\
\text { temp. } \\
{ }^{\circ} \mathrm{C} .\end{array}$ & $\begin{array}{l}\text { Mean } \\
\max . \\
{ }^{\circ} \mathrm{C} .\end{array}$ & $\begin{array}{c}\text { Absolute } \\
\max . \\
{ }^{\circ} \mathrm{C} .\end{array}$ \\
\hline $\begin{array}{c}1924 \\
\text { December } \\
1925\end{array}$ & 30 & $177 \cdot 6$ & 1.03 & $9 \cdot 6$ & $0 \cdot 173$ & $26 \cdot 06$ & $67 \cdot 6$ & $79 \cdot 0$ \\
\hline January & 29 & $138 \cdot 0$ & $0 \cdot 82$ & $7 \cdot 7$ & 0.171 & $26 \cdot 39$ & $67 \cdot 8$ & $75 \cdot 5$ \\
\hline February & 26 & $171 \cdot 1$ & $1 \cdot 33$ & $12 \cdot 4$ & 0.202 & $26 \cdot 58$ & $69 \cdot 4$ & $73 \cdot 5$ \\
\hline March & 30 & $152 \cdot 5$ & 1.07 & $10 \cdot 0$ & $0 \cdot 210$ & $26 \cdot 21$ & $66 \cdot 8$ & $73 \cdot 5$ \\
\hline April & 30 & $215 \cdot 7$ & $1 \cdot 13$ & $10 \cdot 6$ & 0.118 & $26 \cdot 61$ & $67 \cdot 6$ & 73.0 \\
\hline May & 29 & $136 \cdot 2$ & 0.47 & $4 \cdot 4$ & $0 \cdot 106$ & $25 \cdot 64$ & $62 \cdot 8$ & $73 \cdot 0$ \\
\hline June & 30 & $255 \cdot 2$ & 0.71 & $6 \cdot 6$ & 0.083 & $25 \cdot 80$ & 64.9 & $70 \cdot 0$ \\
\hline July & 31 & $241 \cdot 2$ & 0.56 & $5 \cdot 7$ & 0.072 & $25 \cdot 29$ & $65 \cdot 0$ & $71 \cdot 0$ \\
\hline August & 31 & $252 \cdot 4$ & 0.83 & $7 \cdot 7$ & $0 \cdot 101$ & $26 \cdot 26$ & $67 \cdot 1$ & $73 \cdot 0$ \\
\hline September & 30 & $264 \cdot 5$ & $0 \cdot 97$ & $9 \cdot 1$ & 0.110 & $26 \cdot 35$ & $68 \cdot 5$ & $73 \cdot 0$ \\
\hline Oetober & 31 & $221 \cdot 4$ & 1.03 & $9 \cdot 6$ & $0 \cdot 144$ & $26 \cdot 34$ & $70 \cdot 7$ & $77 \cdot 5$ \\
\hline November & 30 & $165 \cdot 4$ & $0 \cdot 77$ & $7 \cdot 2$ & $0 \cdot 140$ & $26 \cdot 35$ & $65 \cdot 1$ & $77 \cdot 5$ \\
\hline & 357 & $2391 \cdot 2$ & $0 \cdot 89$ & 一 & 0.1325 & $26 \cdot 16$ & 66.98 & $79 \cdot 0$ \\
\hline
\end{tabular}

centage of annual total" the figures have been reduced to a common basis of a month of 30 days. "Mean shade temperature," supplied by the Observatory, is based on the 24 hourly means. The "black bulb" readings are taken from a single black-bulbed thermometer in vacuo, constructed to record maxima; it has not been compared with any standard instrument, and its readings are probably too high $\mathbf{1}$.

A distinct seasonal difference in the amount of distillate per day or per hour of sunshine is observable, and no doubt it will become more regular when the readings for a period of years are obtained. The month of May 1925 was exceptional; $23.58 \mathrm{in}$. of rain fell at the Apia Observatory; the normal is $5 \cdot 51$ in. The seasonal difference which I have demonstrated is something hitherto unknown in the climate of Apia, though a meteorological station has been maintained there for many years. Moreover the seasonal difference in the amount of radiant heat received may be presumed to have a direct effect on plant and animal life.

Fortunately it was possible to standardize one of my radiation integrators. The original pyrheliometer made and described by Gorczynski is installed at the Apia Observatory. It consists of a thermopile of 80 elements of constantan and manganin, which are maintained normal to the sun by clockwork and shielded from other sources of radiation. The resultant current is recorded on a revolving drum. This actual instrument has been standardized by Kimball, against Marvin and Abbot's silver-disc pyrheliometer, and we know that 1 scale division of the drum of Gorczynski's instrument $=4$ millivolts $=0 \cdot 228$ gram calories, per square centimetre per minute. During four days of bright

1 The black bulbed thermometer in vacuo has been compared with the instrument in use at the Rothamsted Experimental Station, during June and July, 1926, by the kindness of Dr B. A. Keen. The instrument used in Samoa gives readings which are always higher than the other: at $60^{\circ} \mathrm{C}$, the difference was between $3^{\circ}$ and $4^{\circ} \mathrm{C}$, but it was not a constant difference. It was not possible to obtain readings beyond $60^{\circ} \mathrm{C}$. 
sunshine in June 1925 there were 2118 gram calories recorded by the Gorczynski pyrheliometer. During the same days 4 c.c. alcohol were distilled by my instrument $A$, which was installed at the Observatory side by side with the pyrheliometer. Therefore one calorie produced 0.0019 c.c. of distillate. Corresponding figures for days of continuous bright sunshine in other months are as follows:

\begin{tabular}{|c|c|c|c|}
\hline Month & & $\begin{array}{c}\text { Days } \\
\text { bserved }\end{array}$ & Distilled per calorie \\
\hline June & & 4 & 0.0019 \\
\hline$\ldots$ & $\cdots$ & 9 & 0.00185 \\
\hline gust $\ldots$ & $\ldots$ & 6 & 0.00175 \\
\hline ptember & $\ldots$ & 6 & 0.0021 \\
\hline hole period & $\ldots$ & 25 & 0.0019 \\
\hline
\end{tabular}

It has to be remembered that this standardization was made on days of continuous bright sunshine in Apia; it is not necessarily accurate under other conditions. The thermal efficiency may be different in places in which the intensity of radiation is greater or less than it is in Apia. But taking the figures just given, as the latent heat of vaporization of alcohol is 200 calories per c.c., one calorie should distil 0.005 c.c. of alcohol : actually it distils 0.0019 c.c. The thermal efficiency of the apparatus is therefore 38 per cent.

Remembering that instrument $A$ which has been standardized distils 125 c.c. under conditions which cause instrument $B$ to distil 100 c.c., and that this relation is nearly constant over a period of months (p. 290), we may say that $B$ distils 0.0015 c.c. alcohol per calorie received. From Table III we know the volume of distillate recorded by $B$ for 12 months of 30 days each, which gives us the following numbers of calories received by that instrument per month.

$\begin{array}{lllrlr}\text { January } & \mathbf{1 6 , 4 4 0} & \text { February } & 26,520 & \text { March } & 21,300 \\ \text { April } & 22,620 & \text { May } & \mathbf{9 , 4 8 0} & \text { June } & \mathbf{1 4 , 1 6 0} \\ \text { July } & 11,340 & \text { August } & 16,560 & \text { Sept. } & 19,440 \\ \text { Oct. } & 20,520 & \text { Nov. } & 15,300 & \text { Dec. } & \mathbf{2 0 , 4 2 0}\end{array}$

Whole year, 214,100.

Various objections have been raised to the instrument in its present form, and some of them can be met.

1. Suppose the radiation to be at a steady rate, and the instrument to be distilling at a corresponding steady rate. Then if the rate of radiation increases there will be a lag before the instrument begins to distil at a correspondingly increased rate.

A partial answer to this criticism is that later in the day the intensity of radiation will decrease and there will be a compensatory lag before the instrument's rate of distillation is decreased. But if sunshine and cloud constantly succeed one another at short intervals, then the radiation received may warm the alcohol and establish an increased vapour density in the upper part of the bulb; diffusion through the air contained in the instrument is slow, and when the sun is obscured the alcohol which has been vaporized may condense back into the bulb, and not distil over into the stem. At the end of such a day the distillate will be very much less than would correspond 
to the amount of radiation which has been received. This could be avoided, if the inner bulb and the stem were exhausted of air. If this were done distillation would not be hindered by diffusion through the air, and alcohol would begin to be received in the stem as soon as radiation heated the bulb. The thermal efficiency of the instrument would then approach 100 per cent. The volume of distillate would be much greater and one would have to modify the design of the instrument accordingly.

2. When several instruments were set up side by side the individual errors were irregular, so that it required several months to standardize one against another; some of the instruments gave readings which could not be compared at all. Part of this irregularity is probably due to the instruments being exhausted to different degrees of completeness so that some of them are cooled by wind, others not. Instruments should be connected to a powerful vacuum pump, after the inner bulb is blackened, and then baked for a period of hours, to avoid this source of error. Part of the errors of individual instruments are also due to the fact that the swan necks. were pulled off by the glass blower, so that they differ sightly in bore and in length. This would be avoided if the instrument were made to the design shown in Text-fig. 2. It is important that the length and cross-section of the stem be exactly equal in different instruments.

3. As distillation proceeds the amount of alcohol in the bulb becomes less, and this lessens the thermal capacity of the bulb.

I see no way of avoiding this, except by reading the instrument before the bulb is seriously depleted. In Samoa the daily distillate from a 10 c.c. bulb was never more than 3.5 c.c. and rarely more than 2 c.c.

4. As distillation proceeds the area from which alcohol is evaporating increases, till the bulb is half empty.

This is true but immaterial; the actual evaporation of alcohol from the surface of liquid in the bulb is rapid, so that a unit of heat will produce a unit of distillate, whether the area of the surface of alcohol be one or five sq. $\mathrm{cm}$. It would be possible to maintain a constant surface area of alcohol if one used a vertical cylindrical bulb, but this appears to me to be unnecessary.

The bulb of the instrument shown in Text-fig. 2 could never be filled above the mouth of the stem, so that the upper part of the bulb on which the radiation falls is some distance from the surface of the alcohol; different parts of the bulb will be at different temperatures, so that the correlation between radiation and distillation will be disturbed. This might be met in two ways. One might employ a bulb of spun copper, blackened externally, hoping that the greater part of the heat received on the upper part of the bulb would reach the alcohol by conduction, but this introduces great technical difficulties in the glass-blowing. It would be simpler to use a glass bulb, blackened from the equator downwards (as shown by the thicker line in Text-fig. 2): the only objection to this is that a very small black surface would be presented to the sun when it is low. 
The zero of graduations on the stem should not be at the bottom, where the stem is rounded and the graduations difficult to read (Text-fig. 1), but further up on the cylindrical part of the stem (Text-fig. 2).

To biologists I believe that it would be of interest to make instruments similar to Text-fig. 2, but without the exhausted glass bulb. Such an instrument run side by side with a similar one in vacuo, might be expected to give information about the heating effect of the solar radiation, less the cooling effect of wind and convection currents; these are the factors to which the plants and animals are exposed. One would not expect such an instrument to be accepted by the physicists.

I should never have carried this work through without the help and advice which I constantly received from Andrew Thomson, the Director of the Apia Observatory; in particular all the work of standardization was his. I am also greatly indebted to my friends N. K. Adam and E. A. Milne, who have helped me in many ways.

\section{SUMMARY.}

The "Radiation Integrator in Vacuo" is an instrument designed by a biologist, to assist in the study of solar radiation, as received on the surface of the earth. The principle of the instrument is that a black bulb in vacuo is exposed to the sun's rays; the bulb, which contains alcohol, is connected to a graduated stem maintained at shade temperature; radiant heat from the sun causes alcohol to distil over the bulb into the stem where its volume is measured. In Samoa the shade temperature is practically constant throughout the year, but one believes on theoretical grounds that more radiation is received from the sun between September and March than at the other season, and that the radiation has two maxima, in October and February. This instrument, which has been observed for 12 months, confirms the expectation. The daily mean distillate, the distillate per hour of sunshine (Campbell Stokes) and the mean distillate for the three hours before noon, all show the same seasonal changes.

The instrument has been standardized against Gorczynski's pyrheliometer, so that the readings in c.c. of alcohol can be converted into calories. The instrument is not difficult to make or read, and it can be left in the open in all weathers. It integrates its results and requires to be read once a day in Samoa.

\section{REFERENCES.}

Dictionary of Applied Physics (edited by R. Glazebrook), III. 702.

Gorczysskt, L. (v. 1924). On a Simple Method of Recording the total and partial Intensities of Solar Radiation. Monthly Weather Review, 52. 299-301.

KimbaLL, H. H. (vi. 1924). Intercomparison of Pyrheliometers. Ibid. 52. 302-303.

(MS. received for publication 31, v. 1926,--Ed.) 